Investigaciones Fenomenológicas, vol. Monográfico 4/II (2013): Razón y vida, 245-277. e-ISSN: $1885-1088$

\title{
El problema de la "Realidad" en el marco de LA INFLUENCIA HISPÁNICA EN LA OBRA DE ALFRED SCHUTZ
}

\author{
The Problem of "Reality" in the Context \\ Of Hispanic Influence in the Work Of AlfRed Schutz
}

\author{
Carlos Belvedere \\ Grupo de Estudio sobre Fenomenología y Etnometodología/ \\ Universidad de Buenos Aires, Argentina \\ cbelvedere@sociales.uba.ar
}

\begin{abstract}
Resumen: En este trabajo paso revista a las diferentes acepciones del concepto de realidad en la obra de Alfred Schutz y las tensiones que lo surcan. Así es que describo una dimensión pragmatista de la realidad, y muestro cómo ella entra en contradicción con una idea marcadamente realista y objetivista. En este contexto, la obra de Schutz se presenta como atravesada por una tensión irresuelta en tres frentes problemáticos: realismo - constructivismo; egología - intersubjetividad; relativismo - fundacionalismo. La intrepretación schutziana del Quijote ilustra magníficamente de qué modo operan estas contradicciones. Al respecto, si bien Schutz se siente cercano a la exégesis de Ortega y Gasset, argumentamos que su Quijote es más afín al de Unamuno. Otra diferencia sustancial que lo distancia de Ortega, a pesar del profundo respeto que sentía por él, es el modo en que ambos cuestionan concepciones colectivistas de lo social como la de Durkheim: Schutz considera que lo social es abstracto $y$, por ende, irreal, mientras que Ortega lo concibe como una realidad sustituta. Además, Schutz piensa que lo social se enfrenta al individuo, mientras que Ortega muestra que se contrapone a la interacción.
\end{abstract}

Palabras clave: Realidad social, sentido, Schutz, Don Quijote, Ortega y Gasset.

\begin{abstract}
In my paper I review the different meanings of the concept of reality in the work of Alfred Schutz and the tensions that cross it. I describe a pragmatic dimension of reality and then I show how it clashes with an idea remarkably realistic and objectivist. In this context, Schutz's work is presented as crossed by an unresolved tension on three fronts: realism - constructivism; egology - intersubjectivity; relativism - foundationalism. The Schutzian intrepretación of Don Quixote superbly illustrates how these contradictions operate. In this regard, although Schutz felt close to the exegesis of Ortega y Gasset, I argue that his Quixote is more akin to that of Unamuno. Another substantial difference with Ortega, despite the deep respect Schutz had for him, is the way in which both challenge collectivist social concepts like Durkheim's: Schutz considered that the social is abstract and therefore unreal, while Ortega conceived it as a substitute reality. Also, Schutz thinks that the social is opposed to the individual while Ortega shows that it opposes interaction.
\end{abstract}

Key Words: Social Reality, Meaning, Schutz, Don Quixote, Ortega y Gasset. 
El "problema de la realidad" ha sido una de las inquietudes persistentes de Alfred Schutz. Tanta gravitación tiene en su obra, que ha titulado el primer volumen de sus escritos "El problema de la realidad social" -volumen que, dicho sea de paso, incluye dos textos capitales al respecto, cuyos títulos también aluden a la "realidad"-. La problemática vuelve a aparecer en el volumen II, en un célebre trabajo sobre Don Quijote. Nuevamente, la "realidad" ocupa importantes páginas en la reseña de Ideas II publicada en el volumen III de los escritos de Schutz, así como en los capítulos dos y seis del volumen VI. Finalmente, la descripción profunda y detallada de la "realidad suprema" que es el mundo de la vida cotidiana, le da tema y ocupa incontables páginas en su obra última (en coautoría con Thomas Luckmann), Las estructuras del mundo de la vida. De modo que podría decirse que Schutz siempre estuvo involucrado con la realidad. Más técnicamente dicho, el problema de la realidad ha tenido una alta pertinencia en su obra.

Ahora bien, pertinencia no es precisión. Por significativa que fuese para Schutz la cuestión de la realidad, hay que decir que el modo en que la encara no está exento de ambigüedades. Nuestro propósito en el presente trabajo es, primero, reseñar las consideraciones de Schutz sobre "el problema de la realidad"; luego, señalar ciertas aporías a las que su planteo conduce, tanto en lo que respecta a su concepción de "la realidad" en sentido amplio cuanto en lo que concierne, más específicamente, a la "realidad social"; a continuación, señalar algunas deficiencias en su concepción de lo social a partir del contrapunto con Ortega y Gasset (en quien Schutz se referencia para tratar esta cuestión); $y$, finalmente, establecer, con base en este cotejo, puntos ciegos en la concepción schutziana de la "realidad social" que dejan abierta una problemática para futuras investigaciones.

\section{1. ¿QUÉ ES LA "REALIDAD"?}

Schutz tiene una concepción pragmatista de la "realidad". Una de sus influencias más notorias y constantes es William James, filósofo para el cual "la 
realidad significa simplemente una relación con nuestra vida emocional y acti$v^{\prime \prime}{ }^{1}$. Esto significa -según interpreta Schutz- que "el origen de toda realidad es subjetivo", de modo que todo lo que existe y despierta nuestro interés, es real. Decir que una cosa es "real", es decir que "se encuentra en cierta relación con nosotros" ${ }^{2}$.

Ahora bien, la realidad no es monolítica ni homogénea sino que está estructurada en órdenes diversos, "cada uno de los cuales tiene su propio estilo especial y separado de existencia" ${ }^{3}$. Otro pragmatista, George Herbert Mead, ha sido quien -a gusto de Schutz- describió de manera descollante el "núcleo [co$r e]^{4}$ de la realidad", a saber, "la estructuración de la realidad de la cosa física [...] en su relación con la acción humana, y en particular con la manipulación concreta [actual] de objetos con las manos" ${ }^{\prime 5}$.

Esta región -a la cual Mead denomina "área manipulatoria", y que constituye para Schutz "el núcleo de la realidad"- incluye los "objetos que son vistos y manejados [handled], a diferencia de los objetos distantes, que no pueden ser experimentados por el contacto, pero están situados en el campo visual" ${ }^{\prime 6}$. Es por ello que únicamente estas "experiencias de cosas físicas dentro del área manipulatoria permiten la prueba básica de toda realidad: la resistencia; solo ellas definen los que Mead llama los 'tamaños [sizes] estándar' de las cosas que aparecen fuera del área manipulatoria en las deformaciones [distortions] de las perspectivas ópticas"7 ${ }^{\prime 2}$ Así, por ejemplo, la percepción visual de un objeto distante conlleva la anticipación de que puede ser traído al contacto con nosotros "mediante la locomoción, en cuyo caso la perspectiva deformada de los objetos desaparecerá y se restablecerán sus 'tamaños estándar'" ${ }^{8}$.

Schutz hace propia "esta teoría del predominio del área manipulatoria", a punto tal de expresar que ella "converge" con su propia tesis "de que el mundo

\footnotetext{
${ }^{1}$ Schutz, Alfred. El problema de la realidad social. Escritos I, Buenos Aires, Amorrortu, 2003, p. 197.

${ }^{2}$ Idem.

${ }^{3}$ Idem.

${ }^{4}$ Considerando la temática en cuestión, he preferido seguir aquí la traducción al español del texto de Schutz. En los casos en que considero que la expresión del texto en inglés tiene una riqueza o multiplicidad de sentidos no asibles enteramente por su equivalente en español, incluiré entre corchetes la palabra en inglés. Este recurso también servirá para mantener continuidades dentro de un mismo campo semántico que inexorablemente se pierden en la traducción, donde es preciso a veces recurrir a distintos términos. A su vez, en sentido contrario, permitiría mantener distinciones que de otro modo se perderían en las homonimias. Cuando el término en inglés vaya entre paréntesis y no entre corchetes, corresponderá a especificaciones introducidas por el traductor.

${ }^{5}$ Schutz, Alfred. El problema de la realidad social, p. 210.

${ }^{6}$ Idem.

${ }^{7}$ Idem.

${ }^{8}$ Idem.
} 
de nuestras ejecuciones [working], de los movimientos corporales, de los objetos que se manipulan y las cosas que se manejan, y de los hombres, constituye la realidad específica de la vida cotidiana" ${ }^{9}$ - siendo para Schutz la vida cotidiana, como bien se sabe, la realidad suprema-.

Sin embargo, la teoría del "área manipulatoria" no es tomada por Schutz de manera lineal sino que la resignifica incluyendo este ámbito -"que el individuo experimenta como núcleo [kernel] de su realidad"- en la esfera más amplia de lo que denomina, en sus propios términos, "mundo a su alcance (world within his reach)", el cual incluye lo que hay más allá de su vista y su oído, así como "las zonas adyacentes abiertas a su ejecutar potencial"10. Otro cambio significativo que introduce Schutz es "hablar de provincias finitas de sentido", en vez de áreas manipulatorias, a las cuales podemos darles el "acento de realidad"11, poniendo así de relieve que "es el sentido de nuestras experiencias, y no la estructura ontológica de los objetos, lo que constituye la realidad"12. De modo que esos ámbitos finitos de sentido serán o no reales según les demos o no el sentido de ser reales; lo cual, por supuesto, significa también que podemos despojarlos de ese sentido, que podemos retirarles el acento de realidad a todos y cualesquiera de estos ámbitos, excepto uno: el "mundo del ejecutar cotidiano [working in daily life]", que constituye ni más ni menos que "el arquetipo de nuestra experiencia de la realidad"13, siendo todos los demás modificaciones suyas.

Así es que, el pensamiento de sentido común presupone el mundo de la vida cotidiana y le otorga el acento de realidad en tanto nuestras experiencias prácticas prueban su unidad y congruencia, a punto tal que esta realidad nos parece ser la natural, y la "hipótesis de su realidad" se impone "como irrefutable $^{\prime 14}$. Además de esta razón, Schutz enumera otros cuatro motivos por los cuales el mundo externo de la vida cotidiana es, para nosotros, la realidad suprema:

\footnotetext{
${ }^{9}$ Idem.

${ }^{10}$ Idem.

${ }^{11}$ Ibidem, p. 215. En otros trabajos, donde sigo la edición en inglés de la obra de Schutz, he preferido la expresión "dejo de realidad" porque consideré que expresaba mejor el sentido de la posición de Schutz. Mantendré la versión publicada en español, habiendo expresado ya mis preferencias. El lector podrá, en todo caso, escoger uno u otro término según lo considere mejor.

${ }^{12}$ Schutz, Alfred. El problema de la realidad social, p. 303.

${ }^{13}$ Ibidem, p. 217.

${ }^{14}$ Ibidem, p. 216.
} 
a. Porque siempre tomamos parte en ella, aun durante nuestros sueños, por medio de nuestros cuerpos, que son en sí mismos cosas del mundo externo [outer].

"b. Porque los objetos exteriores [outer] delimitan la libertad de nuestras posibilidades de acción, al ofrecer una resistencia que, si puede ser superada, solo puede serlo mediante un esfuerzo.

"c. Porque es en este ámbito donde nos insertamos [we can gear] por medio de nuestras actividades corporales, y es él por ende, el que podemos cambiar o transformar.

"d. Porque dentro de este ámbito, y solo dentro de él -y esto no es sino corolario de los puntos precedentes- podemos comunicarnos con nuestros semejantes y establecer así un 'ambiente comprehensivo común', en el sentido que da Husserl a esta expresión. ${ }^{15}$

En breve, la vida cotidiana es la realidad suprema porque es permanente, constringente, práctica, y -en definitiva- intersubjetiva. Estos son los rasgos, entonces, que hacen del mundo de la vida cotidiana la realidad suprema para el hombre en actitud natural y que le otorgan el privilegio, que ninguna otra provincia finita de sentido posee, de que pongamos en él de manera permanente el acento de realidad, sin poder jamás retirárselo.

\section{DON QUIJOTE Y SUS PROBLEMAS CON "LA REALIDAD"}

El problema de la realidad es ilustrado en la obra de Schutz con la figura del Quijote. Encontramos tres momentos privilegiados en que esta ejemplificación se desarrolla con cierto detalle. En primer lugar, contamos un capítulo del tomo I de los Escritos de Schutz ${ }^{16}$ donde, en el marco de sus consideraciones sobre la "realidad", el autor esboza una interpretación del Quijote. En segundo lugar, hay dos textos, recogidos en el tomo $\mathrm{VI}^{17}$, en los que Schutz vuelve sobre el Quijote. Allí retoma los elementos principales del trabajo recién mencionado, y a la vez avanza en la consideración del vínculo entre realidad y fantasía. Tomaremos, entonces, a estos textos como un segundo cuerpo a considerar en conjunto, teniendo en cuenta que son ampliamente convergentes. En tercer y último lugar, nos detendremos en el más célebre trabajo de Schutz sobre el

\footnotetext{
${ }^{15}$ Ibidem, p. 304.

16 "Sobre las realidades múltiples", en ibidem, pp. 197-238.

${ }^{17}$ Schutz, Alfred. "The Problem of Personality in the Social World" $y$ "Genesis of the Social Person in the Solitary Self", en Collected Papers VI. Literary Reality and Relationships, Phaenomenologica 206, Dordrecht, Springer, 2013, pp. $199-240$ y $265-309$.
} 
tema, que es su artículo sobre "Don Quijote y el problema de la realidad social $^{\prime 18}$, incluido en el tomo II de sus escritos. Es, ciertamente, la versión más extensa y minuciosa en cuanto a su interpretación del texto cervantino, de modo que nos dará ocasión de ampliar y profundizar el análisis. Además, su significación para el lector en lengua española hará que le prestemos una especial atención $^{19}$.

En conjunto, estos textos nos mostrarán -al contrario de ciertas interpretaciones corrientes- que Don Quijote vive por algún tiempo, al menos, en su realidad, que es otra que la del "emisario del sentido común" que le sirve de escudero, lo cual dista mucho de decir que vive en la fantasía. Veamos, entonces, las consideraciones de Schutz sobre este texto capital de la literatura en lengua española.

2.a. En Escritos I, Schutz argumenta que Don Quijote no traspasa las fronteras del mundo del actuar o trabajar ("ejecutar"). En ese sentido, si bien "es un fantaseador [fanstast]", lo que enfrenta son "realidades": "no hay gigantes imaginarios en la realidad de su mundo del ejecutar, sino gigantes reales" ${ }^{20}$. Sólo a posteriori, a partir de los sucesos desencadenados, advierte que su interpretación del objeto fue invalidada por los hechos ${ }^{21}$. Ahora bien, esto no hace de Don Quijote un ser extraordinario sino todo lo contrario, pues la suya es "la misma experiencia que todos tenemos dentro de la actitud natural" ${ }^{22}$ cuando descubrimos que hemos tomado equivocadamente un objeto por otro. Su particularidad, entonces, no radica en que enfrente una realidad distinta sino, simplemente, en que "reacciona de otro modo que nosotros en situaciones similares" $^{\prime 23}$. Don Quijote no es distinto porque el curso ulterior de los acontecimientos desdiga su interpretación inicial del objeto, de la situación o, lisa y llanamente, de la realidad; sino tan sólo porque "no se somete a la 'explosión

\footnotetext{
${ }^{18}$ Schutz, Alfred. "Don Quijote y el problema de la realidad", en Estudios sobre teoría social. Escritos II, Buenos Aires, Amorrortu, 2003, pp. 133-152.

19 "Don Quijote y el problema de la realidad" fue publicado por Schutz en español (en 1954) en la revista Diánoia (anuario del Centro de Estudios Filosóficos de la Universidad Nacional de México) con traducción del profesor Luis Recaséns Siches y su esposa (ibidem, p. 12). Honrando este espíritu, hemos escogido citar a Schutz en español, en aquellos casos en que disponemos de traducciones.

${ }^{20}$ Schutz, Alfred. El problema de la realidad social, p. 220.

${ }^{21}$ Idem.

${ }^{22}$ Idem.

${ }^{23}$ Idem.
} 
de su experiencia', no advierte su engaño [delusion] ni admite que los objetos atacados han sido siempre molinos y nunca gigantes ${ }^{\prime 24}$ sino que,

obligado a reconocer la realidad actual de los molinos a cuya resistencia sucumbió, [...] interpreta este hecho como si no perteneciera al mundo real [...] mediante la teoría de que a último momento, y para humillarlo, su archienemigo, el mago, debe haber transformado los gigantes, hasta entonces reales, en molinos de viento. ${ }^{25}$

Solo entonces "retira Don Quijote definitivamente el acento de realidad del mundo del ejecutar y lo adjudica al mundo de sus fantasías [imageries]"26.

2.b. Desde este punto de vista, Don Quijote no vive inicialmente en un mundo de fantasía. Esto es tratado por Schutz en dos considerables descripciones de "El mundo de la fantasía" recogidas en Escritos VI. Don Quijote no es visto allí como un alienado sino, en todo caso, como un soñador o -según dice Schutz- "un visionario enfrentando realidades"27. Por eso, cuando carga contra molinos de viento, no "imagina [he phantasies]" que ataca gigantes ${ }^{28}$ porque su acción proyectada se encuentra inscripta en su "plan-de-vida" y "el acto volitivo del 'fiat' entra en su proyecto" desde el momento en que "espolea a Rocinante y arremete a fin de realizar lo que ha sido proyectado" ${ }^{\prime 2}$. Por eso Schutz rechaza enfáticamente la interpretación del Quijote como un delirante cuando -tras restituir argumentos que, podemos inferir, le resultaban ingratamente familiares- se pregunta:

¿Es correcta esta descripción? iNo! No hay presente fantasma en el sentido nuestro. Para Don Quijote, quien ya es un Phantast enfrentado por realidades, [...] no hay ningún fantasma presente cuando considera a los molinos de viento como gigantes. Para él, los gigantes reales de este mundo de trabajo están allí y embate contra esos gigantes reales. Solo después descubre que eran molinos de viento. Se engañaba en su interpretación del mundo del trabajo que le estaba predado, aunque del mismo modo en que nos engañamos nosotros cuando dudamos si esa silue-

\footnotetext{
${ }^{24}$ Idem.

${ }^{25}$ Idem.

${ }^{26}$ Idem.

${ }^{27}$ Schutz, Alfred. Collected Papers VI. Literary Reality and Relationships, p. 230.

${ }^{28}$ Ibidem, p. 290.

${ }^{29}$ Idem.
} 
ta a la orilla del bosque es un árbol o un hombre. Hasta ahora todo ocurrió en el mundo real del trabajo de Don Quijote. ${ }^{30}$

No es que todo lo que hace Don Quijote coincida con el actuar del hombre común en actitud natural. Hay algo distinto, pero no es el hecho de que su mundo resulte invalidado por ulteriores experiencias sino el modo en que toma esta contraprueba:

[Don Quijote] no extrae de esta 'explosión de sus experiencias' la consecuencia de que se ha engañado, que no hay gigantes, sino 'en realidad' molinos de vientos. En cambio, llega a la conclusión de que su enemigo, el mago, para hostigarlo, a último momento transformó a los molinos de viento en gigantes. $Y$ con eso en primer lugar, en ese momento, Don Quijote da el 'salto' a la provincia finita de sentido perteneciente a sus fantasmas. Más en particular - de pura necesidad- le otorga realidad a los molinos de viento, pero interpreta este hecho de manera tal que no pertenece a la provincia de sentido de la realidad. Lo que no es composible en el mundo del trabajo, a saber, la existencia de gigantes y magos, y la transformación mágica de molinos de viento en gigantes, es totalmente compatible en la provincia finita de sentido de las fantasías [phantasmas]. ${ }^{31}$

En síntesis, la gran diferencia entre Don Quijote y el hombre en actitud natural "normal" es que, en vez de cambiar el sentido de su realidad, la experiencia de conmoción en su vida cotidiana lo lleva a tomar como real el mundo de la fantasía. Es decir, si hay algo de locura en él, es el intento de asignarle el acento de realidad al mundo de la fantasía. Esto será desarrollado con mayor detalle en el conocido estudio de Schutz sobre el Quijote.

2.c. Tal como dijimos, Don Quijote le asigna el acento de realidad al mundo de la caballería, y desde esa "posición básica [homebase]" interpreta los demás ámbitos de la realidad. Sin embargo, no puede sostener esto por tiempo indefinido ya que, "cuando este mundo privado suyo entra en contacto con el mundo de sus semejantes, ambos, Don Quijote y los demás, deben resolver los conflictos que surgen entre los esquemas dispares de interpretación vigentes [prevai-

\footnotetext{
${ }^{30}$ Idem.

${ }^{31}$ Ibidem, p. 291.
} 
ling] en cada uno de ellos" 32 , lo cual producirá transformaciones profundas e incluso trágicas.

Schutz ilustra este proceso comparando las tres expediciones de Don Quijote, en cada una de las cuales el mundo social que encuentra adopta actitudes radicalmente distintas a la que él adopta en el mundo privado de su fantasía, el cual "tiene un hondo sentido para él" pero es visto por sus semejantes como "un mundo de locura"33.

En la primera expedición, Don Quijote "está solo, empeñado únicamente en un diálogo interior" ${ }^{34}$. Podríamos decir que fenomenológicamente recorre el camino de la egología. No le escapa la objetividad natural del mundo, en el que puede actuar con eficacia práctica: sus acciones son realizables [performable] "dentro de la realidad eminente [paramount] de la vida cotidiana a pesar de sus motivos fantásticos, sin que haga falta ningún encantador para conciliar los esquemas divergentes de interpretación" ${ }^{35}$.

A partir de la segunda expedición, en cambio, "Don Quijote ya no está solo y necesita establecer un 'subuniverso del discurso' con los semejantes con quienes comparte una relación cara a cara dentro del mundo del sentido común" ${ }^{\prime 36}$. Es decir que ya se abre al mundo intersubjetivo, donde las cosas no solo son lo que para él sino lo que para todos. Digamos, entonces, que debe encontrar un modo de vérselas con la inter-objetividad. Aquí cobra relevancia, en el análisis de Schutz, la figura de Sancho Panza, ungido como "representante del pensamiento cotidiano" merced, entre otras cosas, a que siempre tiene a mano un proverbio "para explicar todo en términos del conocimiento presupuesto" $^{\prime 37}$. Lo que el sentido común garantiza es que las cosas y los sucesos que ambos experimentan sean interpretados según los mismos esquemas; es decir, garantiza que las experiencias compartidas sean "comunes" y refieran a "los mismos objetos" ${ }^{\prime 38}$. Lo cual significa que el sentido común establece una de las bases del mundo social, puesto que:

\footnotetext{
${ }^{32}$ Schutz, Alfred. Estudios sobre teoría social, p. 138.

${ }^{33}$ Idem.

${ }^{34}$ Idem.

${ }^{35}$ Ibidem, p. 139.

${ }^{36}$ Idem.

${ }^{37}$ Idem.

${ }^{38}$ Idem.
} 
Nuestra relación con el mundo social se basa en la hipótesis [assumption] de que, a pesar de todas las variaciones individuales, nuestros semejantes experimentan los mismos objetos de una manera sustancialmente similar a nosotros y viceversa, y también que nuestro esquema de interpretación y el de ellos muestran la misma estructura típica de significatividades [relevances]. Si se desploma esta creencia en la identidad sustancial de la experiencia intersubjetiva del mundo, queda anulada [destroyed] la posibilidad misma de establecer la comunicación con nuestros semejantes. ${ }^{39}$

En la tercera expedición de Don Quijote, "la dialéctica de la intersubjetividad es trasladada a una nueva dimensión" ${ }^{\prime 40}$ dado que los semejantes con quienes se encontró en las dos expediciones previas entablaban relaciones cara a cara con él "sin que ninguno de los copartícipes tuviera conocimiento previo del otro $^{\prime 41}$. En cambio, como antes de que iniciara su tercera expedición la historia de sus primeras aventuras había sido narrada en un libro leído por la mayoría de las personas a quienes habría de encontrar en su periplo, Don Quijote enfrenta ahora a un "público anónimo de lectores [que] se ha formado un tipo ideal" de su personalidad, "de su manera de actuar y reaccionar"; de modo que prevé en él cierto tipo de comportamiento, incluyendo sus expectativas respecto de las reacciones de aquellos, y están preparados para orientar su comportamiento hacia el caballero de modo tal que pueda interpretarla como una respuesta adecuada a sus propias acciones ${ }^{42}$. Sin embargo, este encuentro es peculiar: podríamos decir que es irónico ya que se trata de una broma en la que quienes interactúan con Don Quijote hacen de cuenta que el mundo es tal como él espera. Así es que, siguiéndole la corriente, buscan establecer un universo de discurso con él y construyen, dentro de la realidad de su mundo de la vida cotidiana, "un mundo de juego, de broma, de ficción [make-believe] y 'hacer de cuenta' [let's pretend]" que esperan que Don Quijote considere real en los términos de su universo privado ${ }^{43}$.

Pero al no asignar nunca a su mundo de ficción el acento de realidad, no logran establecer con Don Quijote un universo de discurso ni, por consiguiente, pueden en-

\footnotetext{
${ }^{39}$ Idem.

${ }^{40}$ Ibidem, p. 142.

${ }^{41}$ Idem.

${ }^{42}$ Idem.

${ }^{43}$ Idem.
} 
trar con él en una verdadera relación social. Esto conduce, como veremos, a la tragedia personal y al derrumbe del caballero. ${ }^{44}$

Entonces, el encuentro irónico del que hablamos está, en definitiva, condenado al fracaso porque Don Quijote, a diferencia de sus interlocutores, se toma muy en serio el mundo de la caballería. Su tragedia personal llegará cuando su mundo se desmorone porque ha quedado "destruida su capacidad de interpretar la realidad de sentido común en términos de su universo privado" ${ }^{45}$ y porque -en lo que Schutz describe como un "gran proceso de desilusión"- le ha ido quitando "poco a poco el acento de realidad a su subuniverso privado". ${ }^{46}$ Ocurrido eso, queda confinado a "la triste realidad de la vida cotidiana"47.

Este confinamiento es descripto por Schutz en términos de reminiscencias platónicas, cuando en su análisis nos muestra a Don Quijote "encerrado en la realidad cotidiana como en una prisión y torturado por el más cruel de los carceleros: la razón del sentido común"48.

\section{DON QUIJOTE Y SANCHO PANZA: LA IMAGINACIÓN Y EL SENTIDO COMÚN EN LA TENSIÓN PLURALISMO - FUNDACIONALISMO}

Hemos visto a Schutz comenzar su caracterización de Don Quijote como quien enfrenta realidades, y lo hemos visto terminar mostrando su fatal aprisionamiento en la carcelera realidad de la vida cotidiana. ¿Es el mundo del Quijote una realidad tan verdadera como cualquier otra, o es insostenible como tal, debiendo caer ante el peso inexorable de la realidad suprema del mundo de la vida cotidiana? Esta pregunta equivale a esta otra: ¿es la realidad múltiple y diversa, o existe una realidad fundamental, en comparación con la cual las otras, pretendidas realidades, no son más que una quasi realidad? En breve, ¿es Schutz un pluralista o un fundacionalista? Veamos.

Schutz comienza su análisis del Quijote como un pluralista, cuando señala que la realidad suprema del mundo de la vida cotidiana no es tan "monolítica" como parece pues contiene "enclaves de experiencia" que la trascienden y se

\footnotetext{
${ }^{44}$ Idem.

${ }^{45}$ Ibidem, p. 151.

${ }^{46}$ Idem.

${ }^{47}$ Ibidem, p. 146.

${ }^{48}$ Ibidem, p. 151.
} 
refieren a otras regiones de la realidad "no compatibles" con ella. ${ }^{49}$ Así, por ejemplo, el mundo de la fantasía no es una región unificada sino que "hay fantasías dentro de las fantasías, subuniversos dentro de subuniversos, que pueden contradecirse entre sí y con la realidad de la vida cotidiana"50. Además de esta diversidad interna a cada mundo, hay también una diversidad externa en la relación entre mundos, ya que cualquiera de ellos puede valer como real en la medida en que lo consideremos como tal. Hemos dicho que es el sentido de nuestras experiencias y no la objetividad del mundo lo que constituye su carácter de realidad. Así, basta con cambiar el esquema de interpretación vigente en un subuniverso por un esquema válido en otro para "garantizar la coexistencia y compatibilidad de varios subuniversos de sentido que se refieren a los mismos hechos, y asegurar el mantenimiento del acento de realidad otorgado a cualquiera de tales subuniversos" ${ }^{\prime \prime 1}$.

Sin embargo, esta declaración que pareciera pulverizar la realidad, efectúa todo lo contario pues con la misma expresión que celebra su multiplicidad, la reunifica al fundarla en la realidad suprema del mundo de la vida cotidiana y al poner por fuera de todos los subuniversos de sentido "los hechos" -al contrario de la consideración nietzscheana de que no hay hechos; solo interpretaciones-. En concomitancia, Schutz hace derivar su homologación del mundo del Quijote con el del hombre común, en una diferenciación jerarquizante. Si bien sostiene que los argumentos esgrimidos en la realidad de nuestra actitud natural para darle crédito a los sucesos históricos son "similares a los utilizados por Don Quijote: documentos, monumentos, relatos [accounts] autenticados por testimonios, y una tradición ininterrumpida" ${ }^{\prime 2}$, también establece una ruptura radical al afirmar que el subuniverso que Don Quijote toma como punto de partida "no es el de la realidad eminente de la vida cotidiana" ${ }^{23}$.

De pronto, lo que parecía una virtud de Don Quijote, aparece como un defecto consistente en la incapacidad de distinguir la realidad de la irrealidad. Schutz le atribuye a Cervantes este giro, supuestamente introducido en la segunda etapa de redacción del texto. Pero lo cierto es que, en su análisis, es Schutz quien llega a la conclusión de que, a diferencia de Don Quijote, "noso-

\footnotetext{
${ }^{49}$ Ibidem, p. 134.

${ }^{50}$ Ibidem, p. 144.

${ }^{51}$ Ibidem, p. 137.

52 Ibidem, p. 135.

${ }^{53}$ Ibidem, p. 146.
} 
tros, los Sancho Panza del mundo de sentido común" ${ }^{15}$, sabemos diferenciar el mundo de la fantasía del de la realidad. Si bien vivimos, lo mismo que el Quijote, en diferentes ámbitos de realidad, nos percatamos de que la "realidad" del mundo de ficción es de una clase totalmente distinta a la de nuestra vida diaria ${ }^{55}$ porque es el único subuniverso en el que podemos hacer presa con nuestras acciones, al que podemos transformar y cambiar mediante ellas, y dentro del cual podemos comunicarnos con nuestros semejantes. Es gracias a esta característica fundamental del subuniverso de la vida cotidiana que la experimentamos como la realidad suprema en relación con otras circunstancias y ambientes con los cuales debemos habérnoslas ${ }^{56}$.

Así que, por más que ambos mundos tengan su realidad, la realidad en serio, la fundamental, permanente, es la del mundo de la vida cotidiana, mientras que el mundo de la caballería es ya una peculiar modificación suya ${ }^{57}$. Lo que el análisis schtuzeano del Quijote subraya, entonces, no es la capacidad de asignarle el acento de realidad al mundo de nuestra elección, sino todo lo contrario. Así considerada, la experiencia de Don Quijote nos muestra

su fuerza invencible en la experiencia que el mundo de la vida cotidiana -con sus cosas y sucesos, sus conexiones causales de leyes naturales, sus hechos e instituciones sociales- nos es simplemente impuesto, que podemos comprenderlo y dominarlo solo en una medida muy limitada, [...] y que nuestra única esperanza y guía es la creencia de que podremos asimilar [came to terms with] este mundo para todos los fines buenos y prácticos si nos comportamos como los demás, si presuponemos lo que los demás creen fuera de toda duda. Todo esto implica nuestra fe en que las cosas seguirán siendo lo que han sido hasta ahora, y en que seguirá confirmándose en el futuro lo que nuestra experiencia de ellas nos ha enseñado. ${ }^{58}$

De modo que, si bien al inicio del análisis el Quijote nos muestra que la realidad es múltiple y consiste en el sentido de nuestra experiencia, al final nos muestra que la realidad fundamental es una y que se nos impone irremediablemente. Esta percatación no solo tiene un tenor cognitivo sino también moral. Don Quijote experimenta una suerte de metanoia cuando, ante a las mentiras de Sancho Panza

\footnotetext{
${ }^{54}$ Ibidem, p. 145.

${ }^{55}$ Idem.

${ }^{56}$ Idem.

${ }^{57}$ Ibidem, p. 136.

${ }^{58}$ Ibidem, p. 151-152.
} 
siente la hybris que ha cometido mezclando [intermingling] realidad y fantasía al relatar sus aventuras en la cueva [...] Siente que ha transgredido las fronteras autoestablecidas de la realidad de su ámbito privado, dentro de cuyos límites se ha permitido soñar, superponiendo [intermingling] así dos ámbitos de realidad y pecando contra el espíritu de la verdad. ${ }^{59}$

Esta experiencia es en parte, según la interpretación de Schutz, la de "su 'hermano menor' Segismundo en La vida es sueño, de Calderón" ${ }^{60}$, cuando descubre "que es posible que aun su subuniverso privado, el ámbito de la caballería, sea solo un sueño, cuyos placeres pasan como sombras ${ }^{\prime 16}$. Esto es calificado por Schutz como "la verdadera tragedia de Don Quijote"62. Tal vez en un intento de acercar su interpretación al "maravilloso comentario sobre Don Quijote"63 de Miguel de Unamuno, Schutz le hace descubrir al Quijote -por así decirlo- el sentimiento trágico de la vida.

\section{LA DUDA CARTESIANA Y LAS APORÍAS DE LA REALIDAD COMO ÉNFASIS}

Calderón y Unamuno al margen, lo cierto es que el Quijote de Schutz no es un canto a la diseminación del sentido y que el personaje ha terminado por recibir un trágico baño de realidad. ¿Cómo interpretar estas definiciones? Intentaremos tres respuestas distintas aunque compatibles y que, en conjunto, permitirán una comprensión más cabal de la problemática schutziana de la realidad. No en vano el sintagma recurrente en Schutz es "el problema de la realidad"...

El texto schutziano está surcado por tres ejes problemáticos que plantean una tensión irresuelta: realismo - constructivismo; egología - intersubjetividad; relativismo - fundacionalismo. En efecto, de un lado, Schutz considera que es el sentido de nuestras experiencias lo que constituye la realidad; de otro lado, deja pendiente -cual la cosa en sí kantiana- una estructura ontológica de los objetos que pareciera ser autónoma respecto de las significaciones que le asignamos. De un lado, la realidad es construida por el ego solitario (de hecho, su semblanza inicial de Don Quijote lo pinta prácticamente como un caballero

\footnotetext{
${ }^{59}$ Ibidem, p. 150.

${ }^{60} \mathrm{Idem}$.

${ }^{61}$ Ibidem, p. 151.

${ }^{62}$ Idem.

${ }^{63}$ Ibidem, p. 150.
} 
de la egología); de otro, la intersubjetividad termina por imponerle un sentido irrecusable a ese yo inmerso en su propia realidad, capaz de actuar en el mundo sensible y transformarlo, esto es, de operar sobre la objetividad remanente, incluso si es incapaz de entablar una comunicación efectiva con otro ser humano. De un lado, el mundo al cual le asignamos el acento de realidad será la realidad misma en tanto podamos operar pragmáticamente en él, sea cual fuere el que hayamos elegido; de otro lado, ninguno de esos mundos se genera ni sostiene por sí mismo sino que todos ellos son variaciones del mundo de la vida cotidiana, sobre el cual descansan inexorablemente.

Estas tres ambigüedades no sólo se aprecian en la interpretación schutziana del Quijote sino que surcan toda la ontología social de Schutz. Su obra misma está atravesada por la tensión entre una interpretación realista y otra constructivista, ya que en recurrentes pasajes se lo ve oscilar entre la idea de que el mundo tiene una estructura ontológica propia, y la idea de que es nuestra asignación de sentido lo que le da su carácter de realidad. Lo mismo ocurre con la tensión entre la egología, que parece estar supuesta (aunque nunca asumida de manera explícita) en algunos de sus análisis ${ }^{64}$, y la convicción de que la intersubjetividad es un datum de la vida cotidiana, de modo que siempre es preciso partir de la descripción del nosotros viviente como primer estrato de nuestras experiencias. Igualmente, la tensión entre relativismo y fundacionalismo aflora en otros tramos de la obra de Schutz, por ejemplo, en su teoría del símbolo, que preserva el carácter de realidad relativa de los demás subuniversos de sentido, pero a la vez le asigna en exclusiva el carácter de realidad suprema al mundo de la vida cotidiana.

No obstante, cabría interpretar la teoría del símbolo como un fruto maduro que, en la obra tardía de Schutz, presenta la mejor solución a estas tensiones al articular lo que aparecía con menor claridad en su interpretación del Quijote. El recurso a la teoría del símbolo en Schutz resuelve estas tensiones del lado del realismo, de la intersubjetividad, y de la vida cotidiana -tres problemáticas que se articulan entre sí, con una mayor coherencia y claridad en los textos tardíos de Schutz-. Lamentablemente, esto lleva a Schutz a tesis cercanas al

\footnotetext{
${ }^{64}$ Véase Embree, Lester, "Dorion Cairns and Alfred Schutz on the Egological Reduction", en Hisashi Nasu, Lester Embree, George Psathas, Ilja Srubar (eds.), Alfred Schutz and his Intellectual Partners, Konstanz, UVK Verlagsgesellschaft, 2009, pp. 177-216.
} 
realismo que lo alejan en cierta medida de la fenomenología estricta ${ }^{65}$. Lo cierto es que el diferendo entre Don Quijote y Sancho Panza termina por resolverse a favor de este último, y la condena a muerte de aquellos prisioneros platónicos, en la caverna del dogmatismo de la actitud natural y el sentido común, se rubrica inapelablemente, dejando el sabor amargo de la triste realidad cotidiana que se alza victoriosa sobre los sueños vividos como realidad por el "visionario" Don Quijote.

Pero el triunfo de la "realidad" no es sencillo ni inmediato. Para llegar a ella y asirnos a la certeza (dogmática, pero poco importa al fin) con que se le impone al "hombre común", hemos de atravesar la prueba de fuego de la duda cartesiana. Schutz nos muestra entonces a un Quijote meditabundo, quien, en la visión de la cueva de Montesinos, "duda y sigue dudando acerca de si lo que vio" allí "era realidad, sueño o pura ficción elaborada por él mismo" ${ }^{\prime 66}$. Entonces pregunta

si su relato de las experiencias que ha tenido en la cueva era verdad o sueño, imaginación o realidad, y dos veces se le responde que ha sido una mezcla de ambas cosas. Es que, aun dentro del subuniverso del mundo privado de Don Quijote, existe la posibilidad del sueño y la imaginación, un mundo de fantasía dentro del mundo de la fantasía; aun en este subuniverso, las fronteras de la realidad son inestables [gliding]; aun aquí hay enclaves que constituyen reflejos de otros subuniversos. ${ }^{67}$

Una de las principales diferencias entre la realidad eminente del mundo de la vida cotidiana y la cuasi realidad del mundo de la fantasía es su fragilidad, en el sentido de que no es sino a base de enormes esfuerzos y de manera nunca definitiva que podemos vivirlo como real. Esa fragilidad conlleva una inestabilidad de modo que, a la larga, el acento de realidad volverá a caer sobre la realidad fundamental del mundo de la vida cotidiana. Por eso es que el intento del Quijote estaba condenado de antemano al fracaso. Lo mismo que el intento de Schutz por sostener la validez de los subuniversos de sentido distintos a los de la vida cotidiana. De modo que su fracaso es el mismo que el de Don Quijote: ninguno logra asignar de manera definitiva e incuestionable el acento de reali-

\footnotetext{
${ }^{65}$ En particular, véanse las críticas de Ronald Cox, Schutz's Theory of Relevance: A Phenomenological Critique, La Haya, Martinus Nijhoff, 1978.

${ }^{66}$ Schutz, Alfred, Estudios sobre teoría social, p. 143.

${ }^{67}$ Ibidem, p. 144
} 
dad a un subuniverso distinto al de la vida cotidiana. Uno y otro terminan por doblegarse ante la monotonía gris de la habitualidad. En definitiva, entonces, es Schutz su Quijote.

\section{LAS APORÍAS DE LA REALIDAD SOCIAL}

Los problemas de Schutz con "la realidad" distan mucho de ser una quijotada pues ni son ilusorios ni han comenzado con su lectura de Cervantes, sino que conforman el nudo gordiano de su ontología social.

En efecto, la ontología social de Schutz se estructura con base en la oposición entre familiaridad y anonimia ${ }^{68}$, lo cual implica -tal como señala Natanson- una distinción entre realidad (familiaridad) y abstracción (anonimia) ${ }^{69}$. El mismo Schutz lo explicita al establecer que el mundo social se ordena según grados de intimidad y anonimia en torno al self como centro. Al respecto, entiende que solo en la situación cara a cara puedo captar a mis semejantes como individuos, mientras que en las restantes regiones del mundo social sólo puedo experimentar su comportamiento típico, su patrón típico de motivos y actitudes en un grado creciente de anonimidad ${ }^{70}$. Según Schutz, entonces, intimidad y anonimia son "categorías" que organizan el mundo ${ }^{71}$ y "categorías de nuestra interpretación del mundo"72 jerarquizadas, según su grado de realidad, entre familiaridad y anonimia.

En este marco, Schutz considera que la relación cara a cara es el grado cero de la realidad social y que es aprehendida directamente, en el presente viviente, a diferencia de otras experiencias (tales como la de los contemporáneos, los predecesores, etc.), que son aprehendidas indirectamente por medio de tipificaciones, las cuales son patrones y tipos ideales que forman parte de la propia reserva de conocimiento acerca de la realidad social en general ${ }^{73}$. Entonces, tenemos de un lado el presente viviente, aprehendido directamente en la

\footnotetext{
${ }^{68}$ Respecto de esta cuestión, véase Kimura Masato, "From Intimacy to Familiarity: On the Political constitution of the Life-World", en: Cheung Chan-Fai y Yu Chung-Chi (ed.), Phenomenology 2005, 1. Selected Essays form Asia. Part 1, Zeta Books, cap. 11, pp. 311-334.

${ }^{69}$ Véase Maurice Natanson, Anonimity. A Study in the Philosophy of Alfred Schutz, Bloomington, Indiana University Press, 1986.

${ }^{70}$ Schutz, Alfred. El problema de la realidad social, p. 285.

${ }^{71}$ Schutz, Alfred. Estudios sobre teoría social, p. 77.

${ }^{72}$ Ibidem, p. 107.

${ }^{73}$ Ibidem, pp. 54.
} 
relación cara a cara y, del otro, las demás experiencias, aprehendidas indirectamente por medio de nuestro conocimiento común acerca de "la realidad social en general".

Así, por ejemplo, Schutz considera que en el mundo de nuestros contemporáneos nunca encontramos personas vivientes reales sino tipos ideales ${ }^{74}$, puesto que distingue la comprehensión conceptual predicativa del tipo ideal, de la "realidad social" viviente, de modo que cualquier tipificación que no refiera a relaciones inter-individuales carece de realidad. En consecuencia, su ontología social se extiende desde la insondable realidad de la vida individual hasta las aprehensibles abstracciones del conocimiento social; esto es, entre la certeza absoluta de mis experiencias inmediatas de mi semejante y mi experiencia mediata e incierta de mis contemporáneos.

Por lo expuesto, el orden creciente de anonimato en los tipos ideales es para Schutz correlativo del distanciamiento de la realidad social directamente vivenciada. Así, sucumbe ante la tentadora simplicidad de la falsa oposición entre la vida individual (concreta y real) y la colectividad social (abstracta y ficticia). Esto tiene una doble consecuencia: de un lado, pone a lo individual antes de lo social; por el otro, pone a lo social por fuera de la realidad. Hay en esto una dificultad por vincular ambas dimensiones; o, lo que es igual, una dificultad por dotar a lo social de realidad; y a la realidad, de un carácter social. Vemos, entonces, que esta ontología social se extiende entre la realidad inalcanzable de la subjetividad recóndita y la irrealidad asible del anonimato, entre la absoluta certeza de mis propias vivencias y la incerteza de la existencia de mis contemporáneos. ¿Puede, entonces, haber alguna realidad en lo social?

La tesitura schutziana hace difícil pensar con precisión la idea de una realidad social. Por un lado, Schutz no abandona esta expresión, que -como se ha visto- es recurrente en su obra; pero por otro, tiende a colocar la realidad del lado del individuo de carne y hueso y no de lo social en cuanto tal. En efecto, ya en su primera obra publicada, Schutz establece que toda tipificación que no remita a relaciones interindividuales carece de realidad. Así, por ejemplo, en el mundo de los contemporáneos -que se estructura según grados crecientes de anonimización y según una concomitante pérdida gradual de concreción de los

\footnotetext{
${ }^{74}$ Alfred Schutz, La construcción significativa del mundo social. Introducción a la sociología comprensiva, Barcelona, Paidós, 1993, p. 233.
} 
tipos ideales- ${ }^{75}$ "nunca encontramos gente viviente real" sino que "siempre tratamos con tipos ideales"76. A su vez, la concreción de los tipos ideales "será mayor según la facilidad con que pueda [...] pasar de una comprensión meramente conceptual y predicativa a una captación inmediata de la persona misma"77. De modo que la antinomia entre familiaridad y anonimato funge como gradiente que ordena la ontología social de Schutz. De un lado, tenemos el presente viviente de la relación-Nosotros, en su concreción y familiaridad; del otro, están los tipos superiores que componen la reserva (stock) de conocimiento. En este sentido, lo social sería abstracto y, por lo tanto, no tendría una realidad aparte de las relaciones reales entre individuos vivientes.

\section{LA REALIDAD SOCIAL EN EL ENCUENTRO DE SCHUTZ CON ORTEGA}

La principal consecuencia, para nuestra problemática, de la antinomia schutziana entre la realidad de la vida individual y la irrealidad de las abstracciones sociales es que -como se dijo- hace imposible hablar de "realidad social". Creemos que esta indefinición podrá pensarse mejor en relación con Ortega, con quien Schutz tiene fuertes afinidades e incluso convergencias programáticas $^{78}$, especialmente en lo que concierne a la descripción fenomenológica de la actitud natural ${ }^{79}$, no obstante las diferencias que subsisten entre ellos ${ }^{80}$.

Schutz descubre a Ortega cuando, mientras preparaba sus extensos ensayos sobre Scheler, encuentra su elogio del pensador alemán. Esto despertó su

\footnotetext{
${ }^{75}$ Ibidem, p. 230.

${ }^{76}$ Ibidem, p. 233.

77 Ibidem, p. 224.

${ }^{78}$ Además, quedan constancias de que Ortega había leído a Schutz pues, en El hombre y la gente, lo menciona tres veces: una, como discípulo de Husserl ocupado seriamente en elaborar una concepción de la "sociedad"; otra, como quien "dice muy bien [...] que mientras trato a los Tús envejecemos juntos"; una tercera, como partidario de "la doctrina tradicional [...] según la cual el tú sería un alter ego" (Ortega y Gasset, José. El hombre y la gente, pp. 154, 162 y 164).

${ }^{79}$ Schutz considera que, lo mismo que él, Ortega "permanece en la actitud natural", si bien se siente perplejo porque su colega no se interesa en sus mecanismos constitucionales: "¿Y qué, si no la constitución, habría de requerir explicación?" (Nasu, Hisashi, "Anotations in Schütz's Books. José Ortega y Gasset (VI, 6/25)", en Alfred Schutz's Library, edición en CD, p. 4). Agradezco encarecidamente a Hisashi Nasu por su generosa autorización para consultar y citar este documentado y valioso trabajo, realizado por él y su equipo, de registro de las anotaciones de Schutz a los libros de su biblioteca personal (que actualmente se encuentra en el Socialwissenschaftliches Archiv de la Universidad de Constanza).

${ }^{80} \mathrm{El}$ reconocimiento de las amplias coincidencias entre ellos no evitó que Schutz remarcara un conjunto considerable de divergencias. Por ejemplo, no coincidía con Ortega en que su enfoque era "completamente diferente al de Husserl y sus seguidores" (incluido él mismo) sino que estaba convencido de que su perspectiva era "completamente compatible" con la suya, y que además eran complementarias (Schutz a Recaséns Siches, citado en Wagner, Helmut R., Alfred Schutz. An Intellectual Biography, Chicago, The University of Chicago Press, 1983, p. 141).
} 
interés en El hombre y la gente, libro que leyó en idioma inglés a principios de 1958. No podría decirse que Ortega ejerció una influencia sobre Schutz sino, más bien, como sugiere Hermida Lazcano, que hubo una "sincronía" entre ambos, ya que la publicacón de El hombre y la gente fue simultánea con la participación de Schutz en el Coloquio Husserl de Royaumont, donde presentó su ponencia sobre el problema de la intersubjetividad trascendental en Husserl. Apenas unos meses más tarde, Schutz leyó el libro de Ortega ${ }^{81}$. Además, las convergencias en torno a ciertos tópicos tampoco bastan para hablar de perspectivas coincidentes ${ }^{82}$. Incluso habría que decir que las críticas son preponderantes $^{83}$.

Sin embargo, cierto es que Schutz veía afinidades profundas con Ortega, más allá de sus diferencias. Así es que, en una carta dirigida a Luis Recaséns Siches, se refiere a El hombre y la gente como "un intento de delinear los fundamentos filosóficos de la sociología" ${ }^{84}$. Schutz consideraba que Ortega, tal como él mismo, partía de la filosofía de Husserl y la sociología de Weber ${ }^{85}$. Con ello, "por ejemplo, los conceptos husserlianos podrían esclarecer el sentido de proyectos que a su vez le dieran sentido a la acción humana; las idealizaciones, las modificaciones atencionales, y los procesos constitucionales a encontrarse en el stock de conocimiento; y las posibilidades abiertas y problemáticas implicadas al elegir" ${ }^{\prime \prime 6}$.

Movido por un profundo interés y entusiasmo, Schutz hace "copiosas y extensas anotaciones al margen" de su ejemplar de El hombre y la gente. Según hace constar Nasu, las anotaciones de Schutz ocupan 213 de las 272 páginas que tiene el libro (es decir, el 78\%).

En algunas páginas los márgenes están casi llenos de anotaciones. Además, Schutz hizo un "índice onomástico" en la primera página en blanco de este ejemplar. Y no quedan dudas de que leyó la edición en inglés consultando la edición original en español y también la traducción alemana, pues corrigió o alteró algunas traducciones

\footnotetext{
${ }^{81}$ Citado en Wagner, Helmut R. Alfred Schutz. An Intellectual Biography, p. 141.

${ }^{82}$ Ibid.

${ }^{83}$ Barber, Michael D. The Participating Citizen. A Biography of Alfred Schutz, New York, State University of New York Press, 2004, p. 214.

${ }^{84}$ Nasu, Hisashi. "Alfred Schutz's Dialogue with Ortega y Gasset", p. 273. Véase también Hermida Lazcano, Pablo. "The Taken-for-Granted World", p. 67n3.

85 Hermida Lazcano, Pablo. "The Taken-for-Granted World: A Study of the Relationship Between A.

Schutz and J. Ortega y Gasset", en Human Studies, 19 (1996), p. 45.

${ }^{86}$ Ibídem.
} 
al inglés haciendo referencia a sus traducciones al alemán y escribió en los márgenes las palabras en español correspondientes al inglés. ${ }^{87}$

Las numerosas anotaciones al texto de Ortega no son ociosas. En una carta a Marvin Farber (datada en febrero de 1958), Schutz "expresó su entusiasmo por el libro y señaló que quería escribir un ensayo sobre él", pues lo consideraba "cercano a su propia obra" 88 . Sin embargo, temiendo verse en la necesidad de explicitar el contexto de la obra para el público norteamericano ${ }^{89}$, pensó que sería mejor traducir su ensayo y publicarlo en español en el anuario mexicano Diánoia, donde ya había publicado su trabajo sobre Don Quijote ${ }^{90}$. También este proyecto quedó inconcluso, no por falta de interés de Schutz, sino por "dificultades en la comunicación"191. Así es que el deseo de escribir un ensayo sobre Ortega no llegó a realizarse. En cambio, la recepción de Ortega quedó circunscripta a dos menciones de su elogio a Scheler ${ }^{92}$, un par de páginas discutiendo su interpretación de Husserl ${ }^{93}$, y una escueta referencia a su concepción del hábito, el uso y la costumbre ${ }^{94}$.

Pues bien, ¿qué nos dice la lectura schutziana de Ortega respecto del problema de la realidad social? La pregunta tiene una doble pertinencia, pues no sólo se impone por su propio peso sino también por el hecho de que la cuestión de la "realidad" no es el foco de atención del análisis de Schutz, sino que apenas es objeto de dos escuetas anotaciones al margen de El hombre y la gen$t e^{95}$. De modo que, aun si en su ensayo sobre Ortega Schutz hubiera tenido mucho que decir sobre el tema, su entusiasmo respecto de las coincidencias entre ambos tal vez haya sido excesivo. De ahí que, a pesar de estas similitu-

\footnotetext{
${ }^{87}$ Nasu estima que las críticas de Schutz a Ortega ocupan al menos el $80 \%$ de las notas, y que se dirigen principalmente a la cuestión del Otro (Nasu, Hisashi, "Alfred Schutz's Dialogue with Ortega y Gasset", pp. 276-277).

${ }_{88}^{88}$ Barber, Michael D. The Participating Citizen, p. 198.

${ }^{89}$ Esta no es la única razón por la cual Schutz abortó su proyecto de publicar un trabajo sobre Ortega en inglés. También el modo en que Marvin Farber respondió a su solicitud de publicar un artículo extenso en su revista, lo hizo desistir (Barber, Michael D. The Participating Citizen, p. 198).

${ }^{90}$ Wagner, Helmut R. Alfred Schutz. An Intellectual Biography, p. 141.

${ }^{91}$ Ibidem, p. 141. Las dificultades aludidas por Wagner se relacionan con circunstancias personales que debió atravesar Recaséns Siches y que demoraron su respuesta por un año, transcurrido el cual Schutz amablemente declinó su pedido (Barber, Michael D., The Participating Citizen, p. 207).

92 Schutz, Alfred. Collected Papers III. Studies in Phenomenological Philosophy, The Hague, Martinus Nijhoff, 1966, pp. 133, 135 y 145.

${ }^{93}$ Schutz, Alfred. El problema de la realidad social, pp. 145-146.

${ }^{94}$ Schutz, Alfred. Collected Papers IV, Dordrecht, Kluwer, 1996, p. 199.

${ }_{95}$ Nasu, Hisashi. "Anotations in Schütz's Books. José Ortega y Gasset (VI, 6/25)", pp. 2 y 6. Tal como recuerda Nasu, Schutz "hizo interesantes anotaciones críticas respecto de la primera razón para llamar 'realidad radical' a nuestra vida, [y] sobre su concepción de 'realidades de segundo grado'" (Nasu, Hisashi, "Alfred Schutz's Dialogue with Ortega y Gasset", p. 283). También reparó en que Ortega "parte de la vida humana como 'realidad radical'" (ibidem, p. 286).
} 
des, Hermida Lazcano recomiende no ceder a la tentación de identificar las "realidades múltiples" de Schutz con los "grados de realidad" en Ortega, pues, si bien ambos refieren a un estrato privilegiado de la realidad -la realidad par excellence-, existen profundas diferencias porque en Schutz se trata de realidades concebidas como meras modificaciones de la realidad fundamental, mientras que en Ortega son grados sucesivos de pseudo-realidad. De ahí que Schutz se niegue a establecer una jerarquía de realidades según su genuinidad y considere que todo el ámbito de lo social es potencialmente accesible ${ }^{96}$. Además, en Ortega, la realidad radical es mi propia vida, que es plenamente reconocible en soledad; mientras que la realidad suprema que describe Schutz es el mundo de la vida cotidiana, que es desde un principio un mundo intersubjetivo ${ }^{97}$. Por eso, la realidad suprema de Schutz es mucho menos crítica que la realidad radical de Ortega, que repele la vida social como banal en comparación con la vida personal genuina ${ }^{98}$.

Tomando como referencia esta realidad cimera, Ortega ordena gradualmente las realidades según sus posibilidades de ser tomadas como verdaderas (si bien -sostiene Hermida Lazcano- su criterio de veracidad es ambiguo e insatisfactorio $)^{99}$. El esquema schutziano, en cambio, es más flexible, y nos da un criterio de identificación y jerarquización de las realidades múltiples más concreto y esclarecedor ${ }^{100}$. Además, por definir las provincias de sentido como finitas, Schutz no las describe en relación con la verdad sino con la coherencia interna de sus experiencias, "considerando que los intentos por hacer compatibles los diversos submundos están, en general, destinados al fracaso"101.

Coincidimos con Hermida Lazcano en que Schutz no es Ortega; y permítasenos agregar una razón más, ligada a la problemática que venimos siguiendo: que, a pesar de su repulsión por la banalidad de lo social, Ortega no deja de buscarlo entre las realidades auténticas, mientras que Schutz lo deja librado a una realidad temporal, pasajera, y meramente simbólica en comparación con la

\footnotetext{
${ }^{96}$ Ibidem, p. 54.

${ }^{97}$ Ibid. Al decir de Hermida Lazcano, para Schutz el mayor problema en Ortega es que atribuye la realidad radical a la vida personal solitaria, donde la vida social e intersubjetiva no tiene cabida fácilmente ("The Taken-for-Granted World", p. 57). Por eso discrepa con él en cuanto considera al Otro como una realidad secundaria (ibidem, p. 52) y piensa que sólo el cuerpo del otro es parte de mi realidad radical e incuestionable mientras que su alteridad e intimidad son trascendencias que percibo como realidades derivadas o de segundo grado (ibidem, p. 55).

${ }^{98}$ Ibídem, p. 55.

${ }^{99}$ Ibid.

${ }^{100}$ Ibidem, p. 55-56.

${ }^{101}$ Ibidem, p. 56.
} 
realidad suprema del mundo de la vida. Esta diferencia puede apreciarse ya en el programa inaugural de El hombre y la gente, donde se declara el objetivo de esa indagación, consistente en:

averiguar si en el repertorio de las realidades auténticas -esto es, de cuanto no es ya reductible a alguna otra realidad- hay algo que corresponda a eso que vagamente llamamos "hechos sociales".

Para eso tenemos que partir de la realidad fundamental en que todas las demás, de uno u otro modo, tienen que aparecer. Esa realidad fundamental es nuestra vida, la de cada cual, y es cada cual quien tiene que analizar si en el ámbito que constituye su vida aparece lo social como algo distinto de e irreductible a todo lo demás. ${ }^{102}$

De modo que, más allá de la valoración que pudiera hacer Ortega de lo social, e incluso admitiendo que no lo concibe como la realidad radical, El hombre y la gente encuentra la sociedad dentro del repertorio de realidades (mitigadas, derivadas, inauténticas, todo lo que se quiera, pero realidades al fin). Por eso es que Ortega busca averiguar la verdad de "esas realidades" que son la nación, el pueblo, el Estado, la ley, el derecho, la justicia social, etc., poniéndose ante "las cosas mismas a que esos vocablos aluden", huyendo de las "ideas o interpretaciones de esas cosas" elaboradas previamente, y recurriendo "de todas las ideas recibidas a las realidades mismas"103. A tales efectos, se retira a la realidad radical de nuestra vida, donde aparecen, se anuncian o denuncian todas las demás realidades.

En nuestra vida ha de manifestarse cuanto para nosotros pueda pretender ser realidad. El ámbito en que las realidades se manifiestan es lo que llamamos Mundo, nuestro mundo primordial, aquel en que cada cual vive y que, en consecuencia, es vivido por él y, al ser por él vivido, le es patente y sin misterio. Esto nos llevó a hacer un inventario de lo que en ese mundo hay, inventario enfocado al descubrimiento de realidades, cosas, hechos a que con precisión cupiera aplicar alguno de los imprecisos sentidos verbales de las palabras "social, socialidad, sociedad". ${ }^{104}$

Nótese, que en su búsqueda de lo social, Ortega encuentra "realidades, cosas, hechos". Sin embargo, no ha dado aún, por el momento, con la sociedad,

\footnotetext{
102 Ortega y Gasset, José. El hombre y la gente, pp. 12-13.

${ }^{103}$ Ibidem, p. 181.

${ }^{104}$ Ibidem, p. 182.
} 
sino tan solo con la "relación social"105 que, a entender de Ortega, se origina en el individuo, en un yo, y se dirige a otro individuo. Por lo tanto, la relación social "es siempre una realidad formalmente inter-individual"106.

Siempre se trata de dos hombres frente a frente, cada uno de los cuales actúa desde su personal individualidad, es decir, por sí mismo y en vista de sus propios fines. En esta acción o serie de acciones vive el uno frente al otro -sea en pro, sea en contra- y por eso en ella ambos con-viven. La relación inter-individual es una relación típica de vida humana, es la humana convivencia. Cada uno en esa acción emerge de la soledad radical que es primordialmente la vida humana, y desde ella intenta llegar a la radical soledad del otro. ${ }^{107}$

Esta idea de la relación social como inter-individual era del gusto de Schutz, quien cree compartir con Ortega la recusación de toda concepción holista de lo social. Por eso, cuando lee en El hombre y la gente que no existe "una 'conciencia social' o 'alma colectiva'"'108 en el sentido de Durkheim, anota al margen: "se distancia de la posición de Durkheim"109. También es del gusto de Schutz la crítica de Ortega a la idea romántica y mística de "vida colectiva":

Se ha querido místicamente, desde fines del siglo XVIII, suponer que hay una conciencia o espíritu social, un alma colectiva, lo que, por ejemplo, los románticos alemanes Ilamaban Volksgeist o espíritu nacional. [...] Pero eso del alma colectiva, de la conciencia social es arbitrario misticismo. No hay tal alma colectiva, si por alma se entiende, y aquí no puede entenderse otra cosa, sino algo que es capaz de ser sujeto responsable de sus actos, algo que hace lo que hace porque tiene para él claro sentido. [...] Al alma colectiva, Volksgeist o "espíritu nacional", a la conciencia social, han sido atribuidas las calidades más elevadas y miríficas, en alguna ocasión incluso las divinas. Para Durkheim, la sociedad es verdadero Dios. ${ }^{110}$

Schutz recoge estas palabras de Ortega casi a la letra, cuando en su ensayo sobre el Quijote dice (tras citarlo reiteradas veces): "no existe nada semejante a un alma colectiva o una conciencia colectiva en el sentido de Durkheim;

\footnotetext{
105 "Nos pareció hallar una realidad que mereciese llamarse trato o relación social, socialidad" (idem). ${ }^{106}$ Ibidem, p. 183.

${ }^{107}$ Idem.

${ }^{108}$ Ibidem, p. 16

${ }^{109}$ Nasu, Hisashi, "Anotations in Schütz's Books. José Ortega y Gasset (VI, 6/25)", p. 6.

110 Ortega y Gasset, José. El hombre y la gente, pp. 177-178.
} 
las relaciones sociales son siempre interindividuales"111. Sin embargo, esta interpretación es algo apresurada o acaso esperanzada por parte de Schutz, pues Ortega no concibe -como sí lo hace Schutz- lo social como un conjunto de relaciones interindividuales. Ortega concibe en estos términos a la interacción social, no a la sociedad -presunta entidad en cuya existencia Schutz no cree en absoluto, lo cual de por sí lo aparta de la posición a la que pretende acercarse-. Por eso no es exacto el parangón entre uno y otro que propone Hermida Lazcano cuando argumenta que Schutz no está lejos de Ortega al concebir la vida humana como una ecuación entre la existencia auténtica y genuina, y la pseudorrealidad de las convenciones sociales que -tal como sostendría Ortega- recubren mi realidad radical, sólo recuperable mediante el regreso a la soledad ${ }^{112}$. Cierto es que Ortega concibe lo social como una realidad sustituta, no genuina, y a menudo ilusoria, pero realidad al fin ${ }^{113}$; en cambio Schutz, que de buen grado admite la realidad de las relaciones intersubjetivas, no le otorga entidad a la sociedad, que es -valga recordarlo- lo que busca Ortega en El hombre y la gente.

Esta confusión por parte de Schutz lo ubicaría, si entendemos bien a Ortega, junto a la mayoría de los sociólogos, quienes

no han conseguido ni siquiera poner el pie en la auténtica sociología porque ya desde el umbral han confundido lo social con lo inter-individual, con lo que parezco anticipar que llamar a esto último "relación social" [...] era un puro error. [...] lo social aparece, no como se ha creído hasta aquí y era demasiado obvio, oponiéndolo a lo individual, sino por contraste con lo inter-individual. ${ }^{114}$

Entonces, si bien para Ortega sólo la realidad radical de mi vida es incuestionable y el resto no son más que realidades presuntas o de segundo grado, ello no significa que sean falsas sino más bien que les falta patencia y radicalidad $^{115}$. Por eso, el mismo Ortega señala como un error la idea de que lo social carece de realidad. Al respecto, ironiza:

\footnotetext{
${ }^{111}$ Schutz, Alfred. El problema de la realidad social, p. 146.

112 Hermida-Lazcano, Pablo. "The taken-for-granted world", p. 53.

113 Hermida-Lazcano, Pablo. "The taken-for-granted world", p. 53.

114 Ortega y Gasset, José. El hombre y la gente, p. 184.

115 Ibidem, p. 52
} 
$\mathrm{Si}$, como se ha creído casi siempre -y con consecuencias prácticamente más graves en el siglo XVIII-, la sociedad es sólo una creación de los individuos que, en virtud de una voluntad deliberada, "se reúnen en sociedad"; por tanto, si la sociedad no es más que una "asociación", la sociedad no tiene propia y auténtica realidad y no hace falta una sociología. Bastará con estudiar al individuo. ${ }^{116}$

Así, Ortega -a diferencia de Schutz- concibe lo social como una realidad, aunque no sea la realidad radical que es mi vida, ni la realidad de la relación social -realidad de segundo grado "pero que conserva el carácter fundamental de lo humano, a saber, que el hecho propia y estrictamente humano es un hecho siempre personal"- ${ }^{117}$. Por el contrario, "la colectividad es, sí, algo humano; pero es lo humano sin el hombre, lo humano sin espíritu, lo humano sin alma, lo humano deshumanizado"118. De modo que, para Ortega, "la realidad social y todo lo que a ella estrictamente pertenece" existe, aunque "es esencialmente ocultativa, encubierta, subrepticia"119: es "una realidad extrañísima", en la que no se había reparado hasta el momento con la suficiente atención, "aunque sea tan clara y tan patente como es, aunque nos es tan envolvente y cotidiana"120.

Sólo Durkheim alcanzó a entrever, confusa y efímeramente, esta realidad, aunque fue "incapaz de pensarla, de traducirla a conceptos y doctrina"121. De modo que la relación de Ortega con el gran sociólogo francés es más compleja de lo que Schutz interpretó, pues -aunque sea "una sociología lo más estrictamente opuesta a la de Durkheim que cabe imaginar" ${ }^{122}$, no se trata simplemente de un distanciamiento de la idea de sociedad, sino más bien de una conceptualización de la misma.

Consciente de los malentendidos que su posición podía suscitar si era vista como una lisa y llana confrontación con Durkheim, Ortega agrega -tras las críticas que Schutz recoge con entusiasmo- que, no obstante haberse equivocado al creer "que el hecho social era el verdaderamente racional, porque emanaba de una supuesta y mística 'conciencia social' o 'alma colectiva' [...], fue él [Durkheim] quien más cerca ha estado de una intuición certera del hecho so-

\footnotetext{
${ }^{116}$ Ortega y Gasset, José. El hombre y la gente, p. 12.

${ }^{117}$ Ibidem, p. 184.

${ }^{118}$ Ibidem, p. 178.

${ }^{119}$ Ibidem, pp. 186-187.

${ }^{120}$ Ibidem, p. 184.

${ }^{121}$ Ibid.

${ }^{122}$ Ibidem, p. 185.
} 


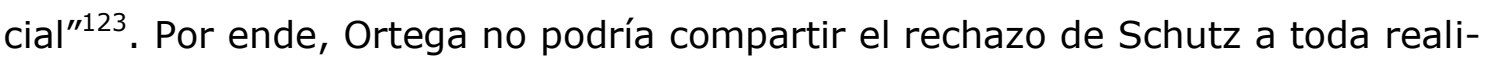
dad que no fuese individual ni su impugnación in toto de la sociología de Durkheim; pero además, sabe que está cerca -peligrosamente cerca- de lo que su concepción de lo social dice a las lecturas de manual. De ahí que recomiende, a quien esté familiarizado con el pensamiento de Durkheim, que en "los dos o tres momentáneos puntos" en que su doctrina "parece como si coincidiese" con la de Durkheim, "rechace esta sugestión" porque le impediría entender sus conceptos, pues se trata de una similitud "ilusoria y desorientadora"124.

La desorientación de la que habla aquí Ortega guarda estrecha relación con las ambigüedades de Schutz: con su oposición binaria entre realidad interinterindividual - irrealidad social. Ortega nos muestra que ni lo social es interindividual, ni carece de realidad -así tenga una realidad monstruosa-. De modo que, en definitiva, lo que está en juego es la distinción entre realidad e irrealidad, y la posibilidad de sostener con largo aliento una realidad que no sea la meramente establecida y aceptada por todos. La peculiar concepción orteguiana del ideal y de la realidad virtual tendrán mucho que aportar a este debate, y habrán de devolvernos a la lectura del Quijote, que es donde ambos pensadores dirimen esta cuestión.

\section{DOS QUIJOTES}

Hemos comenzado mostrando las complejidades del tratamiento que da Schutz a la cuestión de la "realidad", y cómo esa problemática surca su interpretación del Quijote. Luego hemos visto que su recepción del pensamiento de Ortega elide justamente estas dos problemáticas: la de la realidad, y la interpretación del Quijote -acaso porque ambas son solidarias-. De modo que una buena manera de saldar estas cuestiones es, precisamente, comparar los dos Quijotes, el de Schutz y el de Ortega.

Pues bien, por importante que fuese en Ortega el vocablo "realidad", en Meditaciones del Quijote "designa algo equívoco; por un lado está la realidad histórica [...]; y por debajo de ella, sirviendo de suelo, lo que podríamos llamar

${ }^{123}$ Ibidem, p. 16.

${ }^{124}$ Ibidem, p. 184. 
realidad metafísica (nouménica)"125. Así, "la circunstancia o mundo circundante contiene dos planos de realidad: el de la materialidad y el de las representaciones culturales, siempre idealizantes" ${ }^{\prime 26}$.

Hasta aquí, entonces, no estamos lejos de Schutz, en cuyos textos habíamos exhumado una equivocidad semejante al mostrar que el término "realidad" a veces tiene la acepción de asignación de un sentido subjetivo, y otras, la de objetividad remanente. No obstante ello, hemos de admitir que Ortega sabe articular mejor y más profundamente ambas dimensiones, que ya no guardan relaciones biunívocas sino que se encuentran -podríamos decir- en una tensión dialéctica irresuelta pero que busca un sabio equilibrio. Sigamos en esto la interpretación de José Lasaga Medina:

La realidad interpretada y la "materialidad" están en perpetua disputa. Si la primera desplaza a la segunda se corre el peligro de caer en la alucinación (el caso en las culturas de inspiración romántica); si vence la "materialidad" se impone la desilusión (cultura utilitaria). Ortega ve en este dilema un clave metafísica de la vida humana, dividida entre la necesidad de ilusiones (ideales) y el peligro de confundir la interpretación idealizante con la auténtica realidad. ${ }^{127}$

Entre el riesgo de la "alucinación" y el de la "desilusión" -en este "desencaje" entre interpretación y materialidad- ${ }^{128}$ se juega ni más ni menos que lo humano. De modo que "la mirada de Cervantes hace que comprendamos la complejidad de lo real, en la medida en que esa realidad no queda determinada unívocamente por ninguna de las dos instancias que colaboran en su emergencia, la conciencia y el mundo"129. Por eso es que "el 'lugar' de Don Quijote está en el quicio de dos mundos"; idea cervantina con base en la cual "reelabora Ortega los dos planos de realidad antes mencionados, el de la materialidad y el de la interpretación ${ }^{\prime 130}$. En su lectura de Cervantes, entonces, no encuentra un Don Quijote alienado en su imaginación sino uno que comunica "ambos planos de realidad" pues "vive por igual el mundo de la ficción y el mundo de la 'materialidad'"131.

\footnotetext{
${ }^{125}$ Lasaga Medina, José. Figuras de la vida buena, Madrid, Enigma Ediciones, 2005, p. 33.

${ }^{126}$ Ibidem, p. 34.

${ }^{127}$ Idem.

${ }^{128}$ Ibidem, p. 35.

${ }^{129}$ Ibidem, p. 51

${ }^{130}$ Ibidem, p. 52

${ }^{131}$ Ibidem, pp. 55-56.
} 
Esto hace de Don Quijote un realista -y de hecho, este es uno de los puntos en que la interpretación de Ortega es congruente con la de Schutz (aunque solo en su inicio, donde Schutz dice de nuestro personaje que "enfrenta realidades")-. Así es que "el espesor de la propuesta ética orteguiana reside en el rechazo al utopismo que enuncia ideales abstractos e imposibles y la defensa de otros que, sin contener menos riqueza de valor, sea capaz de ejecutarse en lo real"132. No es, entonces, que Ortega renuncie al ideal, sino que intenta "elaborar una teoría del ideal que evite el exceso de la utopía y el defecto del factualismo positivista". ${ }^{133}$ Así, como señala Pons Dominguis, "Ortega no rechaza que las cosas deban ser de una determinada manera, sino más bien el modo en el que según él pretende el idealista que sean, a saber: suplantando la realidad. [...] dicho deber ser puede conseguirse únicamente perfeccionando la realidad ya existente, esto es, desarrollando hasta el límite de sus posibilidades lo re$\mathrm{al}^{\prime \prime 134}$.

Juega aquí un papel importante la idea de "realidad virtual", en tanto permite recuperar la dimensión de lo ideal sin desgajarla de lo real, articulando de un modo más profundo y de mayor espesor las dos dimensiones que hicimos entrar en tensión en la interpretación de Schutz. En este marco, Ortega sostiene, contra el idealismo, que los ideales hay que extraerlos de la realidad misma, "de la virtualidad que anida en lo real"; pues "lo virtual es también realidad, una realidad sui generis, pero tan 'real' como la que reconocemos con los sentidos"135. Entonces, si bien "fantasear es idealizar" (tal como lo muestra también Schutz), cierto es que, para Ortega, "el ideal tiene que ser probado en la resistencia de lo real" ${ }^{136}$.

Vistas así las cosas, el Quijote de Schutz resulta más cercano al de Unamuno que al de Ortega, si es cierto que el de Unamuno -como sostiene Lasaga Medina- "representa el acto de querer fuera del mundo por doble motivo: porque lo que quiere no existe (Dulcinea), pero también porque no acierta a querer nada de lo real-existente. Termina en la melancolía y en la muerte"137. "El

\footnotetext{
132 Ibidem, p. 89.

${ }^{133}$ Ibidem, p. 133

134 Pons Dominguis, Jesús, "Ortega y el idealismo: Don Quijote y Fichte (Una crítica del esfuerzo puro)", en Comunicaciones - Ortega medio siglo después 1955-2005: La recepción de su obra, edición en CD, pp. 2-3).

135 Lasaga Medina, José, Figuras de la vida buena, pp. 133-134.

${ }^{136}$ Ibidem, p. 185.

137 Ibidem,p. 89.
} 
héroe unamuniano, heredero de la ironía romántica, suplanta el mundo con su voluntad. La tragedia de Don Quijote reside en que el mundo se burla de su querer porque su querer inventa, sueña un imposible" ${ }^{138}$. En cambio -tal como señala Cerezo Galán- Ortega lleva a cabo una "confrontación con el quijotismo idealista y místico de Miguel de Unamuno"139. Por eso, bien haríamos en decir con Lasaga Medina: "Lo que 'enseña' Cervantes a Ortega es el perspectivismo, entendido como respeto a la realidad inmediata", entendida como "la unidad del yo y su circunstancia, hombre y paisaje ${ }^{140}$.

El Quijote de Ortega, entonces, va más decididamente que el de Schutz al encuentro de la realidad. Por eso, ante la melancolía en la que se sume, para morir de cordura, el Quijote de Schutz, preferimos aquella cualidad que Ortega elogió en Zuloaga al describirlo como "'un caballero de quijotesca sensibilidad' que corre en auxilio de las cosas, a las que salva del peligro de morir de trivialidad" ${ }^{\prime 141}$.

\section{Sobre los equívocos aCERCA de "LA REALIDAD" en SCHUTZ}

Hemos seguido a Schutz en su quijotesca lucha por no vaciar de sentido la cuasi realidad de los ámbitos finitos de la fantasía y la imaginación, y articularlos con la realidad suprema del mundo de la vida cotidiana. Tristemente, lo hemos visto caer en el desencanto, golpeado por la realidad más brutal que es, también, la más pobre en intensidad y emoción: la de la vida cotidiana. ¿Cómo ha podido ocurrirle esto? Digamos que ha tenido problemas con la realidad. No ha sabido darnos una definición precisa de este concepto medular de su obra. Sin embargo, no es poco lo que ha dicho sobre el tema. Repasémoslo.

En su apropiación del pragmatismo, Schutz define la realidad como "lo que existe y despierta nuestro interés". El acento está puesto, entonces, en nuestro interés; pero -por obvio que resulte- para que algo nos interese, debe comenzar por existir. De modo que el origen de las aporías sobre la realidad que hemos comentado aquí, se encuentra en la misma concepción de la que parte

\footnotetext{
${ }^{138}$ Ibidem, p. 90.

139 Cerezo Galán, Pedro, "Cervantes y El Quijote en la aurora de la razón vital", en J. Lasaga, M. Márquez, J. M. Navarro y J. San Martín (eds.), Ortega en pasado y en futuro. Medio siglo después, Madrid, Editorial Biblioteca Nueva, 2007, p. 22.

${ }^{140}$ Lasaga Medina, José, Figuras de la vida buena, p. 44, 68.

${ }^{141}$ Ibidem, p. 36.
} 
Schutz, la cual se halla tensionada en dos direcciones contrarias: en un sentido, el origen de toda realidad es subjetivo; en otro, la realidad se sustenta en las existencias objetivas. Así, la idea de que una cosa es real si se encuentra en relación con nosotros resulta problemática pues presupone la cosa misma como anterior a su relación con nosotros -o, si se prefiere, como una existencia con derecho propio, independiente del interés pragmático que pueda o no suscitarnos-.

Solo siendo una objetividad autónoma, puede la cosa dar sustento a la realidad subjetiva de la que nos habla Schutz, ya que la prueba básica que debe afrontar la realidad es la resistencia que ella ofrece a nuestras acciones y movimientos corporales en el área manipulatoria. Son, entonces, nuestras experiencias prácticas en el mundo de la vida cotidiana las que prueban la congruencia y unidad de la realidad.

Sin embargo, la realidad no es monolítica sino que está estructurada en órdenes diversos, entre los cuales se destaca como realidad presuntamente natural aquella propia del mundo de la vida cotidiana. Esta es, entonces, la realidad suprema, en virtud de su carácter permanente, constringente, práctico e intersubjetivo. En contraste con el mundo de la vida cotidiana, ningún otro ámbito de la realidad puede ser vivido como tal de manera permanente.

Uno de los motivos principales por los cuales los ámbitos finitos de sentido distintos del de la vida cotidiana no pueden persistir como realidad, así sean vividos subjetivamente como tales, es que no tienen validez intersubjetiva porque son, según Schutz, mundos privados. Por lo tanto, los demás no los viven como reales en el mismo sentido que uno, de modo que no llega a establecerse una verdadera relación social dada la disparidad de esquemas de interpretación existentes. Esta discrepancia obtura la posibilidad de compartir una realidad de sentido común y por lo tanto de vivir un mismo mundo.

Otro motivo por el cual sólo el mundo de la vida cotidiana puede prevalecer como realidad, es que únicamente en él podemos actuar efectivamente $y, a$ través de esa acción, podemos transformarlo. De modo que aquí hay algo más que la mera asignación subjetiva de sentido: cuenta, de manera singular, la operatividad. Como dijimos, la prueba de la realidad de algo es su resistencia a nuestros movimientos corporales. Nada de eso ocurre en los demás subuniversos de los que nos habla Schutz. 
Ahora bien, el mundo de la vida cotidiana no sólo es el ámbito de nuestras acciones prácticas, donde realizamos el fiat voluntario de cambiar el mundo, sino también todo lo contrario: se nos impone irremediablemente y de una manera que nos pinta, no como los Sancho Panza del sentido común en la interpretación schutziana del Quijote, sino al contrario, como los Quijotes derrotados por la triste realidad de la cotidianidad anodina. Este es, entonces, el tercer motivo por el cual tomamos al mundo de la vida cotidiana como la realidad suprema: porque no tenemos más remedio; es decir, porque se nos impone irremediablemente.

Se abre aquí otro interrogante en la obra de Schutz. ¿De qué imposición social nos habla? La inquietud surge porque Schutz considera que toda relación social es siempre interindividual. Si, tal como él sostiene, no hay conciencia colectiva ni cosa semejante y, por lo tanto, lo social no es más que un conjunto de relaciones interindividuales, entonces no hay realidad social que nos pueda ser impuesta. Habrá, sin duda, imposición de un individuo sobre otro, pero sería una imposición personal; a menos que tenga razón Ortega, y entonces lo social sea una realidad distinta, que surge en oposición a la interacción social y no en oposición al individuo, como se creyó por tanto tiempo. Pero Schutz, en su humanismo (encomiable por otros motivos, aunque no por este), quiso concebir la sociedad en términos de un conjunto de relaciones interpersonales y no como lo que es: algo no inhumano pero sí deshumanizado. Su oposición binaria y anacrónica entre individuo y sociedad no le permitió ver más allá del individuo, perdiendo así la realidad social que tan denodadamente buscó en el lugar equivocado.

Este binarismo estéril le impide a Schutz ver que no somos Sancho Panzas sino Quijotes orteguianos, viviendo en el quicio de dos mundos, en el desencaje entre interpretación y materialidad, mediante el voluntarioso esfuerzo por comunicarlos. La tarea no es, entonces, articular el subuniverso de la fantasía con el mundo de la realidad sino componer una realidad compleja y única integrando sus dos dimensiones, la del sentido y la de la materialidad. En definitiva, será mejor pensar la realidad eminente no como un orden en particular sino como una unidad compleja. El mundo de la vida no es la realidad fundamental, sino la realidad, única y plural, pues no hay otra vida que la cotidiana. Es lo que Ortega llamaba la "realidad virtual". Así, la fantasía, la imaginación, el simbolismo en general, no están fuera del mundo de la vida sino en su horizonte. 
Ganaríamos con esto, entonces, lo que Ortega exigía: el respeto por la realidad inmediata en toda su complejidad y riqueza. 